\title{
Constraints on frequent or continuous lactation
}

\section{By Christopher H. KNIGHT, Hannah Research Institute, Ayr KA6 5HL}

Lactation length and frequency are variable. It is likely that the biological norms for the cow are very different from what is imposed on that species by man, for instance. Nor is it only man who moves the goalposts; lactating rodents which mate at the post-partum oestrus will start their subsequent lactation very much sooner than those (of the same species) which do not. Even seasonal breeders (and therefore seasonal lactators) are flexible; goats can be induced to produce three lactations in the time normally taken for two (Knight \& Wilde, 1988). How is this adaptability achieved? Since milk production entails numerous concerted metabolic adaptations, constraints are inevitably imposed at many levels, from the whole animal to the molecular. Complete coverage is beyond the scope of this presentation, which instead will concentrate on the mammary gland itself, and in particular the secretory cell population. I shall attempt to show that limitations imposed at this level are few in number, and that the mammary gland's developmental strategy is actually remarkably adaptable. Those constraints which do exist are, however, crucial ones, which will be difficult to overcome. As far as the dairy cow is concerned, lactation frequency is probably already optimal, and continuous lactations are a long way off.

\section{Cellular changes during lactation}

Recent attempts to partition variation in milk yield between changes in cell number and cell activity are summarized in Fig. 1. Although gland size and milk yield are significantly correlated in goats at peak lactation (Linzell, 1966), the contribution made by post-partum proliferation of cells to the increase in yield which occurs during early lactation is relatively small in this species (Fig. 1(a); Knight \& Peaker, 1984; Wilde et al. 1986), whereas in the mouse the contribution is greater (Fig. 1(b); Knight \& Peaker, 1982a; Shipman et al. 1987).

Changes during declining lactation are of greater significance in the present context. Loss of cells is almost entirely responsible for the decline in milk yield of goats after peak lactation (Fig. 1(a)); proportional decreases in milk yield and cell numbers are very similar (Knight \& Peaker, 1984) and measurements of enzyme activities and in vitro lactose and casein synthesis rates show that the activity of the remaining cells does not decrease (Wilde et al. 1986). If one could prevent this loss of cells, by increasing either cell longevity or cell proliferation, continuous lactation might become a reality.

This idea is supported by experiments in which yield has been increased, and the cellular events studied. In the short term (days to weeks) increased yield is achieved through enhanced activity of pre-existing tissue, but in the long term (weeks to months) increased cell number is responsible (Fig. 1(c)). This has been shown in goats milked thrice-daily unilaterally to increase yield in one gland only (Wilde et al. 1987) and in hemi-mastectomized goats as a compensatory response to removal of one gland (Knight, 1987). Grigor et al. (1984) have observed the short-term cell activity response in rats, and Shipman et al. (1987) have demonstrated the long-term cell number response in mice, in both cases as a result of manipulating litter size or age to increase yield.

\section{Frequent lactations}

The aim is to shorten the non-productive or 'dry' period between lactations, and thereby increase lactation frequency. The longest dry periods occur when conception 
(a)
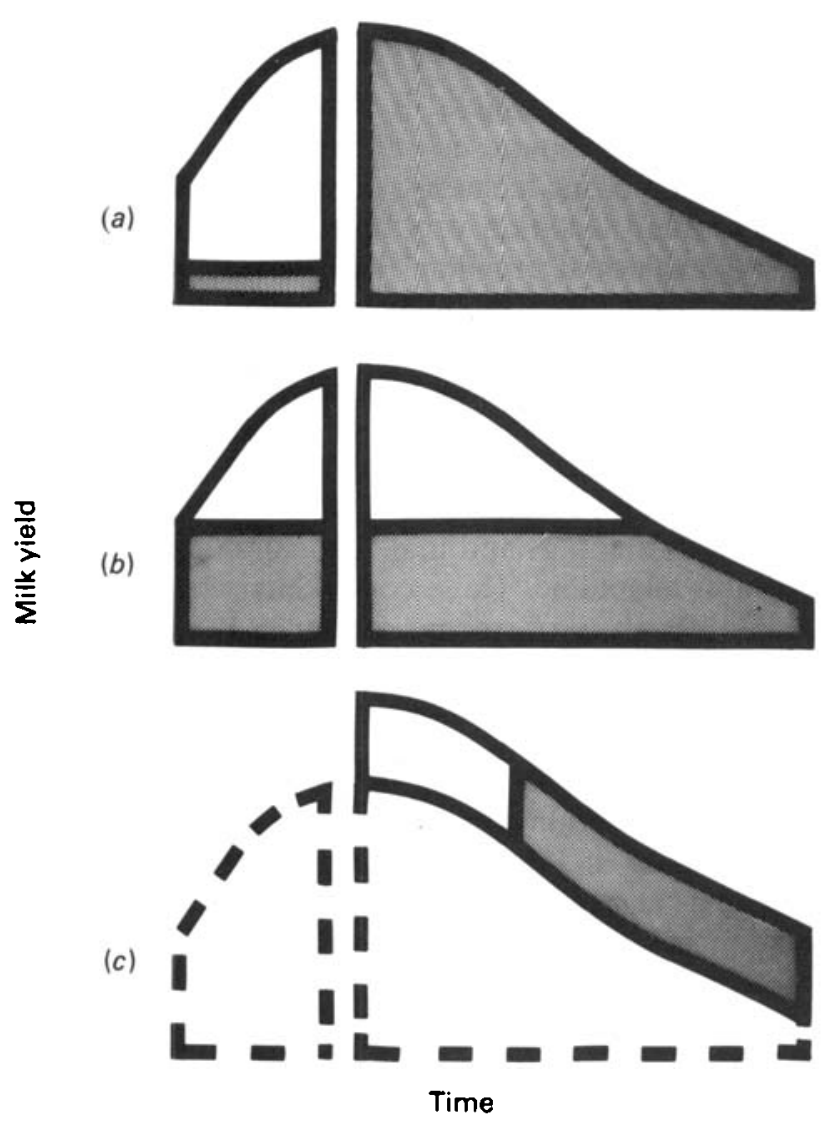

Fig. 1. Schematic representation of the relative contributions of changes in cell number (璠) and cell activity $(\square)$ to changes in milk yield during early and late lactation in goats $(a)$ and mice $(b)$, and during stimulation of milk yield $(c)$. For further details, see p. 45 .

does not take place until after lactation has ceased and the mammary gland has involuted (Fig. 2(a)). There is some dispute concerning the normal extent of involution, i.e. does the gland revert fully to a 'virgin' state or not (for review, see Lascelles \& Lee, 1978). For the present purposes, complete reversion to a hypothetical stem-cell population will be assumed, although it is not suggested that this necessarily occurs in practice. The significant point is that the whole of the subsequent pregnancy is available for glandular redevelopment; proliferation can therefore proceed at the 'normal' rate (i.e. that of the first pregnancy).

Four ways in which the mammary gland could adapt its redevelopment to accommodate a shortened dry period are shown in Fig. $2(b-e)$. The first three models assume that proliferation commences after lactation has ceased. If the gland then redevelops at its normal rate, it will be underdeveloped at parturition (Fig. 2(b)). To regain its usual size, the amount of post-partum proliferation must be increased. In mice, there is evidence for compensatory growth post partum when gestational mammogenesis is reduced, either by 


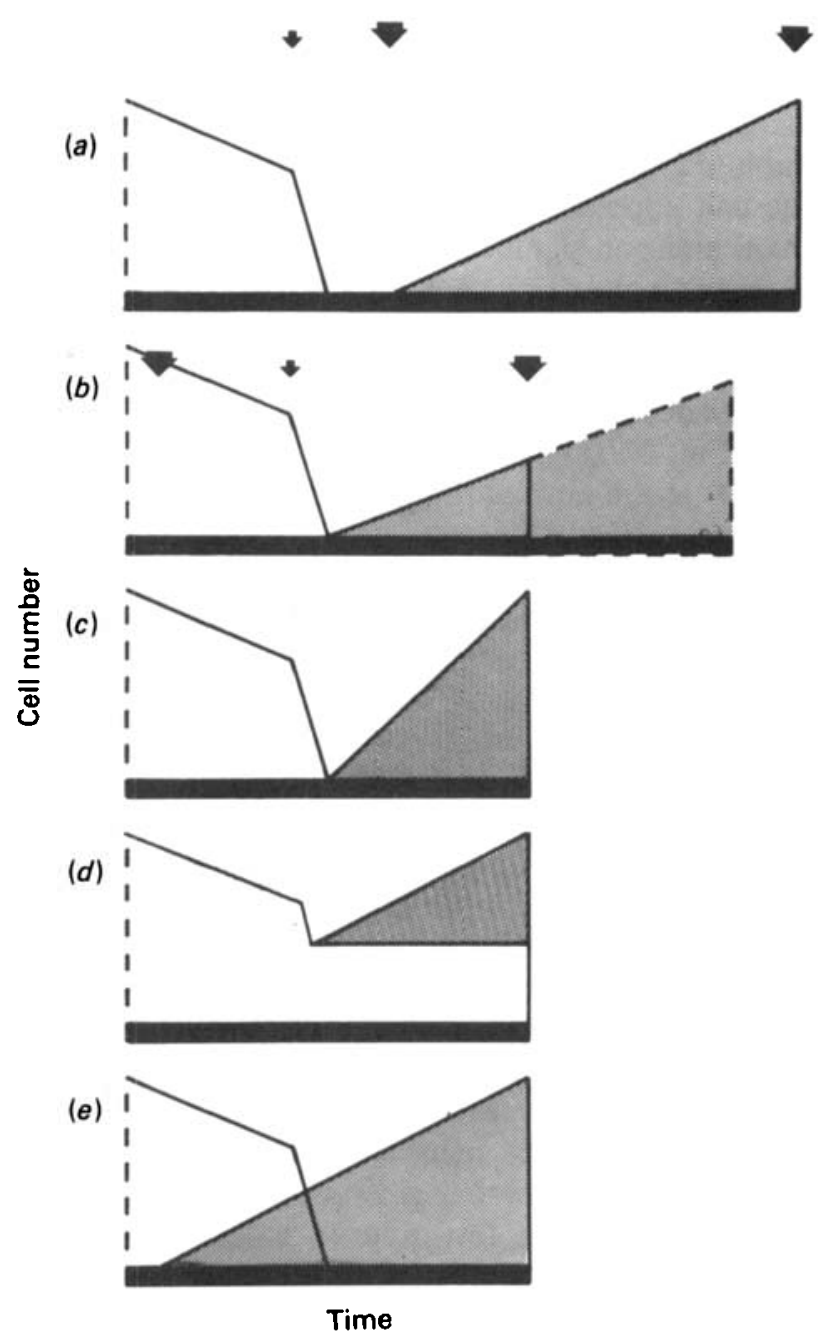

Fig. 2. Schematic representation of mammary redevelopment between lactations. ( $\square$ ), The declining secretory cell population of the first lactation. (T), The population of secretory cells proliferating during pregnancy in readiness for the second lactation. ( $(\boldsymbol{)})$, A hypothetical stem-cell population. $\boldsymbol{\sigma}$, Conception (left) and parturition (right), - Cessation of lactation. (a), Mammary redevelopment when conception follows cessation of lactation. $(b)-(e)$, Possible adaptations to facilitate rapid redevelopment when conception precedes cessation of lactation, i.e. the interval between lactations is shortened. For further details, see p. 46.

decreasing placental lactogen (Knight \& Peaker, 1982b) or by nutritional restriction (Knight \& Peaker, 1982c). Also, the single remaining mammary gland of sheep hemi-mastectomized during pregnancy initially grows at a normal rate, but then undergoes compensatory development around parturition (Davis et al. 1983). Both observations support the potential operation of this model.

A second possibility is that the rate of growth is increased, so that the normal size is attained by parturition (Fig. 2(c)). In Fig. 2, proliferation of cells is shown schematically and simplistically as a linear function of time. Proliferation is actually exponential 
(Knight \& Peaker, 1982a), and the exponent of growth varies across species inversely with gestation length (Sheffield \& Anderson, 1985). I am not aware of any published information on variation of the exponent within a species. Recent findings (C. H. Knight and $\mathbf{J}$. Thomson, unpublished results) suggest that the inhibition of murine mammary growthcaused by reduction of placental lactogen prepartum and of prolactin post partum is due to a reduced growth exponent, rather than to growth starting later or finishing earlier in the inhibited group. However, although there was a significant $15 \%$ difference in the size of the cell population on day 5 of lactation, the difference in the growth exponent was small and non-significant (exponents of 0.117 and 0.108 for control and inhibited groups respectively). This shows that the growth exponent is variable (at least in mice), and that small changes in the exponent will lead to large differences in the amount of growth achieved. This second model, therefore, is quite plausible, but will be difficult to assess statistically.

The third modei (Fig. 2(d)) envisages that proliferation starts only after lactation has finished and proceeds at the normal rate. However, involution of the lactating gland is incomplete, and a proportion of the 'old' cells are carried over into the next lactation, hence the total cell population ('old' plus 'new') is not reduced. Experimental evidence in favour of this model has been obtained in lactating rats, which were mated at the post-partum oestrus and then either made to suckle continuously until parturition and into the second lactation, or allowed an $8 \mathrm{~d}$ dry period between the two lactations (Pitkow et al. 1972). By labelling proliferating cells with tritiated thymidine on day 3 of the first lactation, it was estimated that $73 \%$ of cells present at this stage were carried over to the start of the second lactation in the continuously-secreting rats. This is probably an overestimate; what was actually measured was the carry-over of labelled DNA, which might still have been in the originally labelled cells, but equally might have been in their daughter cells, or in cells which proliferated later and recycled the thymidine label from dying labelled cells. Nevertheless, carry-over of cells was demonstrated and, more importantly, this carry-over was significantly greater in the rats which lactated continuously than in those given a dry period.

If proliferation and secretion were to occur concurrently in the lactating gland then complete redevelopment could be achieved with a normal rate of proliferation, no carry-over of cells and no compensatory growth post partum (Fig. 2(e)). It is known that lactating mammary tissue has a low mitotic index (Traurig, 1967). Nevertheless, differentiated secretory cells are capable of proliferating (Franke \& Keenan, 1979), and cell proliferation has been demonstrated in goat mammary tissue during established lactation (Knight, 1987; Wilde et al. 1987). Significantly, a concurrent pregnancy has been shown to increase cell proliferation in lactating mammary tissue of both goats (Knight \& Wilde, 1988) and mice (C. H. Knight and J. Thomson, unpublished results), suggesting that this model does occur in vivo.

The evidence shows that all four of the models for rapid redevelopment depicted in Fig. 2 are realistic. I suggest that they may operate concertedly to minimize any deleterious effects of short inter-lactation intervals on the mammary gland's subsequent secretory capacity. How effective are these adaptations? In mice, litter weight gain (Mizuno \& Sensui, 1978) and milk yield (Knight \& Docherty, 1985) are quite normal in the lactation that follows a concurrent pregnancy (and therefore a shortened dry period). If this second lactation is also accompanied by a concurrent pregnancy, litter weight gain is actually increased (Thompson \& Anderson, 1977).

Seasonally-breeding goats normally have one lactation per year, and a dry period of several months between lactations. When mated out-of-season at peak lactation (using gonadotrophin-releasing hormone to induce oestrus and ovulation) they will support a 
concurrent pregnancy and lactation and will kid (and lactate) twice in a year with no dry period between lactations (Knight \& Wilde, 1988). Under these circumstances, second lactation yield is reduced compared with a normal second lactation, by about $12 \%$. Some of this reduction may, however, be due to seasonal effects, since goats mated out-of-season start their second lactation in autumn, rather than spring. Overall, milk production is greatly increased (by about $73 \%$ ), since two lactations are possible in one year.

Short or absent dry periods undoubtedly reduce subsequent production in cows, a species in which concurrent pregnancy and lactation is the norm. Part of this effect is most probably related to nutritional and energetic factors, particularly the need to replenish body reserves. There is also evidence for more direct effects on the mammary gland. Swanson (1965) observed a 30\% reduction in milk yield of cows given no dry period compared with their identical twins which did receive a dry period, but nutritional factors could not be entirely ruled out by this approach. Smith et al. (1967) compared individual glands within cows, half milked throughout and half given a dry period of 8-10 weeks. In three of five cows the continuously milked glands subsequently produced less than those given a dry period; in the other two cows there was no difference, but in these animals the yield of the continuously milked glands fell to very low levels prepartum. What is not clear from this work is whether or not total yield was reduced by having no dry period, in other words, was yield constrained at the glandular level or at the whole animal level, and did the difference between individual glands reflect decreases in those milked continuously, increases in the others, or both? Mammary cell number measured shortly before parturition was identical in individual bovine glands given short ( $8 \mathrm{~d})$ and long (48 d) dry periods (Swanson et al. 1967), suggesting that redevelopment is not reduced by a shortened dry period. However, there may be two secretory cell populations showing opposite changes at this time; an increasing population of 'new' cells and a decreasing population of 'old' cells (Fig. 2(e)), hence the usefulness of individual determinations of cell number is limited. For example, in the goat in late lactation cell number is increased by a concurrent pregnancy (Knight \& Wilde, 1988), but in the mouse it is reduced (C. H. Knight and J. Thomson, unpublished results).

\section{Continuous lactation}

The normal cyclical pattern of milk production in the dairy cow inevitably introduces inefficiency, since it includes non-productive periods. Precise reproductive management is essential, but frequently the optimal $365 \mathrm{~d}$ calving interval is not achieved, and the productive life of many cows is cut short by reproductive failure. There is apparently little information published for lifetime milk production. Esslemont et al. (1985) quote several estimates, the highest of which is $18747 \mathrm{~kg}$ in four lactations. If cyclical production could be replaced by a single continuous lactation (i.e. $100 \%$ persistency), a daily yield of $12.84 \mathrm{~kg}$ would be required to produce the same lifetime yield. Continuous production at a higher level (the average Friesian peak yield is about $30 \mathrm{~kg} / \mathrm{d}$ ) or for a longer period (reproduction-related culling would be reduced) would allow major improvements in lifetime yield to be achieved. But is complete persistency a realistic objective?

Goats frequently lactate for extended periods (Mackenzie, 1967); yield gradually declines, although seasonal oscillations may persist for several years (Linzell, 1973). Vandeputte-Van Messom \& Peeters (1982) increased persistency considerably by implanting perphenazine in the median eminence of goats; prolactin is implicated in this 
response but was not measured. Cellular events have not been studied in goats, but some information is available from rodents.

Lactation can be extended in rodents for considerable periods by the simple expedient of regular litter-swapping (young for old) to maintain a strong suckling stimulus (Bruce, 1958). In mice, milk yield is maintained at approximately two-thirds of its peak value (Shipman et al. 1987). I suggested in an earlier section that longer lactations might best be achieved by preventing the loss of cells normally associated with declining lactation, and this proves to be the case; secretory cell number is completely maintained at its peak lactation level during extended lactation in mice (Shipman et al. 1987). A small and transient increase in cell proliferation has been observed $48 \mathrm{~h}$ after a litter swap (C. H. Knight and J. Thomson, unpublished results); however, most of the effect on cell number appears to be due to increased cell longevity. Furthermore, the decrease in yield correlates with a loss of key enzyme activity (particularly fatty-acid synthase (EC 2.3.1.85); Shipman et al. 1987), suggestive of cell ageing. Similar results have been reported by others in both mice (Nagasawa \& Yanai, 1976) and rats (Tucker \& Reece, 1963). In an attempt to prevent the overall loss of cell activity and milk yield, we (C. H. Knight and C. J. Wilde, unpublished results) superimposed on the extended-lactation mouse a mammogenic stimulus (steroid hormones). Cell proliferation was increased, milk yield was initially decreased during treatment but subsequently recovered and was increased in the long term, and enzyme activities (particularly that of fatty acid synthase) were increased.

The conclusion from these various observations is that lactation could become continuous if the size of the secretory cell population could be maintained, and the best yields (greatest persistency) would be achieved by increasing cell proliferation, to replace dying cells, rather than by increasing cell longevity. The extent to which this might be applied to increase dairy cow yield is unknown. Although considerable information is available on the various endocrine and local mechanisms controlling mammary cell proliferation, information pertaining to the cow is scarce, and to the lactating gland almost non-existent. In all probability, a relatively small but maintained shift in favour of factors promoting cell proliferation will be all that is required, since in a large structure (such as the cow's udder) over a long period of time, even a small change in the proportion of cells proliferating at any one time will result, overall, in a substantial number of new cells. This is best illustrated by comparing mid-pregnant and mid-lactation goat udders. Because of differences in the size of these two cell populations, the same total amount of cell proliferation per unit time would be achieved with a mitotic or labelling index of $10 \%$ in the former (typical of pregnant mammary tissue), and only $1.4 \%$ in the latter.

\section{REFERENCES}

Bruce, H. M. (1958). Proceedings of the Royal Society 149, 421-423.

Davis, S. R., Day, A. M. \& Hughson, G. A. (1983). Journal of Dairy Science 66, Suppl. 1, 106.

Esslemont, R. J., Bailie, J. H. \& Cooper, M. J. (1985). Fertility Management in Dairy Cattle. London: Collins. Franke, W. W. \& Keenan, T. W. (1979). Differentiation 13, 81-88.

Grigor, M. R., Sneyd, M. J., Geursen, A. \& Gain, K. R. (1984). Journal of Endocrinology 101, 69-73.

Knight, C. H. (1987). Journal of Reproduction and Fertility 79, 343-352.

Knight, C. H. \& Docherty, A. H. (1985). Journal of Reproduction and Fertility 73, 309.

Knight, C. H. \& Peaker, M. (1982a). Quarterly Journal of Experimental Physiology 67, 165-177.

Knight, C. H. \& Peaker, M. (1982b). Journal of Physiology 327, 17-27.

Knight, C. H. \& Peaker, M. (1982c). Journal of Dairy Research 49, 567-575.

Knight, C. H. \& Peaker, M. (1984). Quarterly Journal of Experimental Physiology 69, 331-338.

Knight, C. H. \& Wilde, C. J. (1988). Journal of Dairy Research 55, 487-493. 
Lascelles, A. K. \& Lee, C. S. (1978). In Lactation, vol. 4, pp. 115-117 [B. L. Larson, editor]. New York: Academic Press.

Linzell, J. L. (1966). Journal of Dairy Science 49, 307-311.

Linzell, J. L. (1973). Journal of Physiology 230, 225-233.

Mackenzie, D. (1967). Goat Husbandry, 2nd edn. London: Faber \& Faber.

Mizuno, H. \& Sensuj, N. (1978). In Physiology of Mammary Glands, pp. 287-302 [A. Yokoyama, H. Mizuno and H. Nagasawa, editors]. Tokyo: Japan Scientific Societies Press.

Nagasawa, H. \& Yanai, R. (1976). Journal of Endocrinology 70, 389-395.

Pitkow, H. S., Reece, R. P. \& Waszilycsak, G. L. (1972). Proceedings of the Sociery for Experimental Biology and Medicine 139, 845-850.

Sheffield, L. G. \& Anderson, R. R. (1985). Journal of Dairy Science 68, 2571-2579.

Shipman, L. J., Docherty, A. H., Knight, C. H. \& Wilde, C. J. (1987). Quarterly Journal of Experimental Physiology 72, 303-311.

Smith, A., Wheelock, J. V. \& Dodd, F. H. (1967). Journal of Dairy Research 34, 145-150.

Swanson, E. W. (1965). Joumal of Dairy Science 48, 1205-1209.

Swanson, E. W., Pardue, F. E. \& Longmire, D. B. (1967). Journal of Dairy Science 50, 1288-1292.

Thompson, L. J. \& Anderson, R. R. (1977). Journal of Dairy Science 60, 126-128.

Traurig, H. H. (1967). Anatomical Record 157, 489-503.

Tucker, H. A. \& Reece, R. P. (1963). Proceedings of the Society for Experimental Biology and Medicine 112, $688-690$.

Vandeputte-Van Messom, G. \& Peeters, G. (1982). Journal of Endocrinology 94, 267-270.

Wilde, C. J., Henderson, A. J. \& Knight, C. H. (1986). Journal of Reproduction and Fertility 76, 289-298.

Wilde, C. J., Henderson, A. J., Knight, C. H., Blatchford, D. R., Faulkner, A. \& Vernon, R. G. (1987). Journal of Animal Science 64, 533-539. 